\title{
Strategi Peningkatan Kinerja Pramusaji Palms Restaurant Hotel Holiday Inn Resort Baruna Bali
}

\author{
Ketut Hepani, Putu indah Rahmawati , Nyoman Dini Andiani \\ Undiksha
}

\begin{abstract}
Abstrak
Penelitian ini bertujuan untuk mengetahui strategi peningkatkan kinerja Pramusaji Palms Restaurant Hotel Holiday Inn Resort Baruna Bali. Subjek dari penelitian ini adalah Supervisor dan Staf Palms Restaurant. Objek penelitian ini adalah Srategi peningkatan kinerja pramusaji Palms Restaurant Hotel Holiday Inn Resort Baruna Bali. Metode pengumpulan data adalah dengan observasi, dokumentasi dan wawancara. Hasil penelitian ini adalah (1) kendala yang mempengaruhi kinerja pramusaji Palms Restaurantt seperti, sulitnya menentukan jadwal pelatihan dikarenan jam operasional yang sibuk, penggunaan cara kerja lama, kekurangan cutleries, dan pesanan telur yang banyak. (2) Strategi yang diterapkan guna meningkatkan kinerja pramusajiseperti pelatihan dan pemberian SOP untuk meningkatkan mutu pelayanan. Pemberian training dan SOP kepada para staf sangat mempengaruhi kinerja kerja pramusaji di Palms Restaurant hal ini dibuktikan dengan meningkatnya score breakfast di Palms Restaurant sehingga mampu mencapai target.
\end{abstract}

Kata kunci: Hotel, Strategi, Kinerja, Pramusaji, Restaurant.

Abstract

This study aims to determine the strategy of improving the perpormance of waitress Palms Restaurant Holiday Inn Resort Baruna Bali Hotel. The object of this research is the strategy of improving the performance of waitress Palms Restauant Hotel Holiday Inn Resort Baruna Bali. The method of collecting data is by observation, documentation and interviews. (1)The results of this study are, constraints that affect the performance o restaurant Palms such as, the difficulty of determining training hours due to busy operating hours, the use of old ways of working, lack of cutleries, and ordering lost of eggs.(2)Strategies implemented to improve the performance of waiterss such as training and provision of SOP to improve service quality. The provision of training and SOP to staff which greatly affects the work performance of waitress in Palms Restaurant.

Keywords: Strategy, Work performance, Waitress, Restaurant, Hotel.

\section{Pendahululuan}

Bali sudah menjadi destinasi internasional dengan berbagai fasilitas pendukung. Salah satu fasilitas pendukung pariwisata yang menguntungkan banyak pihak adalah hotel. Salah satu hotel yang cukup terkenal didaerah Kuta adalah Hotel Holiday Inn Resort Baruna Bali. Salah satu Restaurant di Hotel Holiday Inn Resort Baruna Bali adalah Palms Restaurant yang merupakan All Day Dinning Restaurant yang terletak di lantai 1 berdekatan dengan kolam renang, Restaurant ini dapat menampung 126 seat dan melayani breakfast, lunch, dan dinner, pelayanan jenis breakfast yang digunakan yaitu buffet sedangkan untuk lunch dan dinner adalah menu ala carte. 
Berdasarkan observasi awal selama melakukan PKL penulis menemui bahwa kinerja pramusaji Hotel Holiday Inn Resosrt Baruna Bali dapat dikatakan cukup bagus, namun saat occupancy tinggi kinerja karyawan mulai menurun sehingga menimbulkan keluhan dari tamu, peningkatan kinerja di pengaruhi oleh beberapa faktor internal dan eksternal.

Berdasarkan latar belakang tersebut, maka penulis tertarik untuk meneliti terkait: (1) Apa sajakah yang menjadi kendala dalam meningkatkan kinerja pramusaji Palms Restaurant? (2) Bagaimana strategi meningkatkan kinerja pramusaji Palms Restaurant? Manfaat yang didapat dari penelitian ini adalah yang pertama ada manfaat teoritis: Hasil penelitian ini diharapkan dapat memberi pengetahuan dalam bidang pariwisata dalam hal meningkatkan kinerja pramuaji. dan yang kedua ada manfaat praktis: bagi mahasiswa, hotel dan universitas.

\section{KajianPustaka}

\subsection{Konsep Strategi Kerja}

Menurut Pearce II dan Robinson (2008:2), strategi adalah rencana berskala besar, dengan orientasi masa depan, guna berinteraksi dengan kondisi persaingan untuk mencapai tujuan 10 Perusahaan. Dari definisi tersebut dapat disimpulkan bahwa pengertian dari Strategi adalah sebuah tindakan proses perencanaan untuk mencapai tujuan yang telah di tetapkan, dengan melalukan hal-hal yang besifat terus menerus sesuai keputusan bersamadan berdasarkan sudut pandang kebutuhan pelanggan.

Perencanaan strategis merupakan suatu proses analisis, perumusan, dan evaluasi strategi-strategi yang diterapkan oleh seorang manajer guna mengatasi ancaman eksternal dan merebut peluang yang ada. Tujuan utama perencanaan strategis adalah agar organisasi mampu melihat secara obyektif kondisi-kondisi internal dan eksternal, sehingga organisasi dapat mengantisipasi perubahan lingkungan eksternal. Jadi perencanaan strategis penting untuk memperoleh keunggulan bersaing dan memiliki produk yang sesuai dengan keinginan konsumen dengan dukungan yang optimal dari sumber daya yang ada. Perencanaan dalam pengertian fungsi manajemen adalah pemilih an sejumlah kegiatan untuk ditetapkan sebagai keputusan tentang apa yang harus dilakukan, kapan dan bagaimana melaksanakannya, siapa pelaksananya. Menurut Bryson (2001)

\subsection{Konsep Kinerja}

Menurut Murdijanto (2001:29) menyatakan bahwa: "Kinerja adalah hasil kerja yang dapat dicapai oleh seseorang atau kelompok orang dalam suatu organisasi sesuai dengan wewenang dan tanggung jawab masing-masing dalam rangka upaya mencapai tujuan 
organisasi bersangkutan secara legal, tidak melanggar hukum dan sesuai dengan moral maupun etika." (Murdijanto 2001:29). Standar kinerja merupakan tingkat kinerja yang diharapkan dalam suatu organisasi, dan merupakan pembanding (benchmark) atau tujuan atau target tergantung pada pendekatan yang diambil. Standar kerja yang baik harus realistis, dapat diukur dan mudah dipahami dengan jelas sehingga bermanfaat baik bagi organisasi maupun para karyawan (Abdullah, 2014:114)

Pengukuran kinerja diarahkan pada enam aspek yaitu: Hasil kerja: tingkat kuantitas maupun kualitas yang telah dihasilkan dan sejauh mana pengawasan dilakukan, Pengetahuan pekerjaan: tingkat pengetahuan yang terkait dengan tugas pekerjaan yang ajan berpengaruh langsung terhadap kuantitas dan kualitas dari hasil kerja, Inisiatif: tingkat inisiatif selama menjalankan tugas pekerjaan khususnya dalam hal penanganan masalahmasalah yang timbul,Kecakapan mental: tingkat kemampuan dan kecepatan dalam menerima insturksi kerja dan menyesuaikan dengan cara kerja serta situasi kerja yang ada,Sikap: tingkat semangat kerja serta sikap positif dalam melaksanakan tugas pekerjaan, Disiplin waktu dan absensi: tingkat ketepatan waktu dan kehadiran Menurut Sutrisno (2009). Menurut (Mangkunegara, 2009) kinerja (performance) dipengaruhi oleh tiga faktor yaitu:

Faktor individu,faktor psikologis,faktor organisasi, kinerja individu adalah hasil kerja karyawan baik dari segi kualitas maupun kuantitas berdasarkan standar kerja yang telah ditentukan.Faktor individu ini meliputi kemampuan,latar belakang pendidikanya,keluarga dan tingkat social.Sedangkan demografi meliputi etnis, umur dan jenis kelamin.

\subsection{Penelitian Terdahulu Tentang Strategi Meningkatkan Kinerja}

Table 1 Penelitian Terdahulu Tentang Strategi Meningkatkan Kinerja

\begin{tabular}{|l|l|l|}
\hline Nama & Judul Penelitian & Hasil Penelitian \\
\hline Yuntianto (2015) dan & $\begin{array}{l}\text { Upaya Profesionalisme } \\
\text { KerjaWaiter Untuk } \\
\text { Meningkatkan } \\
\text { Pelayanan Tamu Di } \\
\text { The Grand Palace Hotel } \\
\text { Yogyakarta }\end{array}$ & $\begin{array}{l}\text { Pntuk kemajuan pelayanan waiter terhadap } \\
\text { tamu di The Grand Palace Hotel ini, } \\
\text { pembagian tugas yang diberikan atasan, akan } \\
\text { mempercepat terselesainya semua pekerjaan } \\
\text { secara merata, dalam penguasaan product } \\
\text { knowledge. }\end{array}$ \\
\hline Kusuma (2013) & $\begin{array}{l}\text { Pengaruh Lingkungan } \\
\text { KerjaTerhadap Kinerja } \\
\text { Karyawan Hotel Muria } \\
\text { Semarang }\end{array}$ & $\begin{array}{l}\text { Motivasi kerja dan lingkungan kerja menjadi } \\
\text { salah satu faktor utama yang mendukung } \\
\text { kinerja kerja karyawan }\end{array}$ \\
\hline
\end{tabular}




\section{Metodelogi Penelitian}

\subsection{Rancangan Penelitian}

Dalam rancangan ini menggunakan rancangan penelitian yang bersifat deskriptif yaitu metode yang berupa pencarian data berupa wawancara maupun pengamatanpengamatan lansung kelapangan dan memaparkan hasil pengamatan kedalam bentuk pembahanan. Dalam pelaksanaan penelitian ini mengahasilkan data berupa strategi peningkatan kinerja Pramusaji Palms Restaurant Hotel Holiday Inn Resort Baruna Bali. Dengan sumber data skunder dan primer, juga melalui teknik pengumpulan data melalui wawancara dengan Supervisor Palms Restaurant, juga melakukan dokumentasi serta memproleh data dari sumber skunder seperti buku-buku dan internet yang dijadikan sebagai sumber yang membantu memberikan data yang terkait dengan penelitian ini.

\subsection{Lokasi Penelitian}

Di Indonesia ada 8 Hotel di bawah Intercontinental Hotel Group salah satunya adalah Hotel Holiday Inn Resort Baruna Bali. Hotel yang dibangun dengan gaya kontemporer Bali ini berada di dalam areal seluas 3 hektar. Hotel ini dimiliki oleh Bapak Surya Darmadi yang berasal dari Jakarta. Berlokasi di Jalan Wana Segara 33 Tuban Bali, 80361 Indonesia. Terletak di bentangan Pantai Jerman dan dapat di tempuh 15 menit dari Bandara Internasional Ngurah Rai.

Holiday Inn Baruna Resort merupakan salah satu hotel bintang 5 yang berlokasi di Kuta yang akan memberikan pelayanan terbaik bagi para tamu yang menginap di Holiday Inn Baruna Bali. Salah satu bagian terpenting dari sebuah hotel adalah restaurant sebagai tempat para tamu mengisi perut atau hanya sekedar sebagai temapt bersantai dan bercengkrama bersama, hotel ini memiliki 2 restaurant dengan waktu operasional yang berbeda yaitu Palms Restaurant melayani breakfast, lunch dan dinner. Sedangkan Envy Restaurant khusus melayani lunch dan dinner.Lokasi penelitian ini dilakukan di Palms Restaurant Hotel Holiday Inn Resort Baruna Bali.

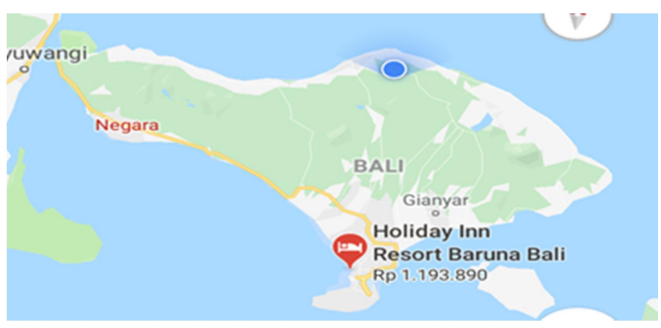

Foto 1

Lokasi hotel pada peta Pulau Bali (sumber : www.google.com. 2019) 


\subsection{Subjek dan Objek Penelitian}

Yang menjadi subyek dalam penelitian ini adalah Supervisor Palms Restaurant sedangkan yang menjadi objek penelitian ini adalah strategi peningkatankinerja pramusai Palms Restaurant Hotel Holiday Resort Inn Baruna Bali.

\subsection{Metode Pengumpulan Data dan Instrumen Penelitian}

Dalam memproleh data didapatkan dengan 3 cara yaitu: wawancara lansung kepada Supervisor Palms Restaurant, dokumentasi teknik pengumpulan data melalui cara mengumpulkan data dengan foto-foto yang nantinya bisa dijadikan sumber data pendukung dalam penelitian dan observasi, observasi dilakukan saat melaksanakan kegiatan trainingselama 6 bulan penuh pada bulan Juni sampai Desember Tahun 2018.

\subsection{Teknik Analisi Data}

Penelitian ini menggunkan teknis analisis data kualitatif Moelong (2008:2) yang berpendapat bahwa penelitian kualitatif merupakan penelitian yang memfokuskan pada paparan kalimat, sehingga lebih mampu memahami kondisi psikologi manusia yang komplek (dipengaruhi oleh banyak fakta) yang tidak cukup apabila diukur dengan menggunkan skala saja.

\subsection{Hasil Penelitian dan Pembahasan}

\section{Kendala Dalam Meningkatkan Kinerja}

Staf Palms Restaurant mayoritas sudah bekerja selama 10 tahun di restaurant tersebut tentu saja mereka sudah hampir 3 kali mengalami pergantian pimpinan di Palms Restaurant, setiap pimpinan baru di Palms Restaurant memiliki kebijakan dan aturan standar sendiri. Maka dari itu terkadang pimpinan baru di Palms Restaurant harus membiasakan kebijakan baru secara perlahan dan berkala agar menjadi kebiasaan baru bagi para staf.

Palms Restaurant sebenarnya adalah restaurant yang sibuk, setelah breakfast para staf perlu mempersiapkan untuk operasional Lunch dan Dinner mulai dari membereskan set up breakfast dan diganti dengan set up table untuk luch dan dinner. Dikarenakan jam operasinal yang padat maka dari itu sulit bagi Pimpinan Palms Restaurant untuk mencari jadwal pelatihan yang tidak menganggu jam operasional. 
Saat occupancy tinggi tentu berpengaruh pada jam oprasional breakfast, kekurangan cutleries adalah salah satu hal yang paling sering terjadi saat tamu ramai. Hal ini terjadi karena saat tamu ramai memerlukan cutleries dengan jumlah banyak dan tamu cenderung tidak mau menunggu lama untuk pengambilan cutleries dan terkadang tidak mendapatkan cutleries yang mereka butuhkan.

Ketika tamu ramai sering makanan di chaving dish habis dan refill makanan lambat sehingga tamu harus menunggu hingga di refill kembali oleh staf kitchen. Seharusnya staf lebih teliti dan berinisiatif untuk segera megisi ulang makanan sebelum makanan tersebut habis. Sehingga tamu tidak perlu menunggu lama dan meninggalkan kesan staf yang tidak peduli dengan tamu.

Di Palms Restaurant para tamu dapat memesan telur dengan menggunakan eegpadl kertas menu khusus berbagai macam omelette dengan beberapa toping, fried egg, poached egg dan boil egg. Tamu yang pertama kali datang atau melakukan breakfast untuk pertama kalinya di Palms Restaurant merasa bingung masalah penggunaan egg pad sehingga terkadang terjadi kesalahan pemesanan karena ketidak pahaman tamu.

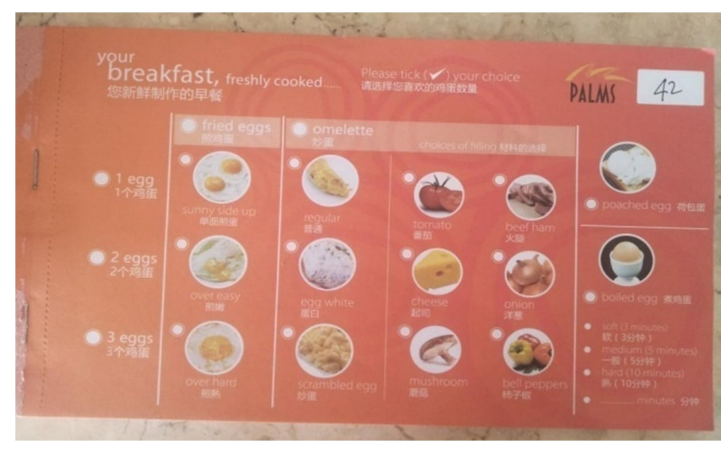

Foto 2 Egg Pad

\subsection{Strategi Meningkatkan Kinerja}

Training atau petatihan kerja biasanya dilakukan secara terjadwal dan sebisa mungkin tidak mengganggu jalannya operasional, biasanya pelatihan kerja dilakukan saat occupancy rendah, sasaran pelatihan kerja adalah seluruh staf Palms Restaurant dilakukan secara terjadwal dan bergilir antar staf.

Untuk menjaga kualitas dan kinerja para staf. SOP merupakan langkah kerja yang wajib dilakukan oleh semua staf.namun bisa saja SOP tersebut direvisi atau di up date sesuai dengan perkembangan yang terjadi di bidang pariwisata atau hospitality.

Dalam meningkatkan kinerja pramusaji Palms Restaurant tentunya diperlukan beberpa strategi yang sudah dijalankan maupun direncanakan namun belum diaplikasikan. Sebagai seorang pimpinan biasanya seorang Supervisor Palm Restaurant 
selalu menerima masukan, kritikan dari bawahan sebagai salah satu acun perencanaan strategi baru.

Pemberian penghargaan biasanya di berikan kepada staf yang berprestasi dalam departmenya masing-masing maupun yang kinerja kerjanya sudah sesuai dengan standar kinerja hotel. Pemberian penghargaan kepada staf hotel biasanya dilakukan dalam kurun waktu 1 tahun sekali dengan beberpa kriteria penilain yang sudah ditentukan.

Pemberian kompensasi kepada staf bukan hanya staf yang berprestasi namun kompensasi biasanya diberikan kepada staf yang turut serta mengikuti kegiatan yang berlansung di hotel. setiap staf akan mendapatkan Hero Card yang memiliki nilai tersendiri dan dapat ditukarkan dengan makanan maupun barang.

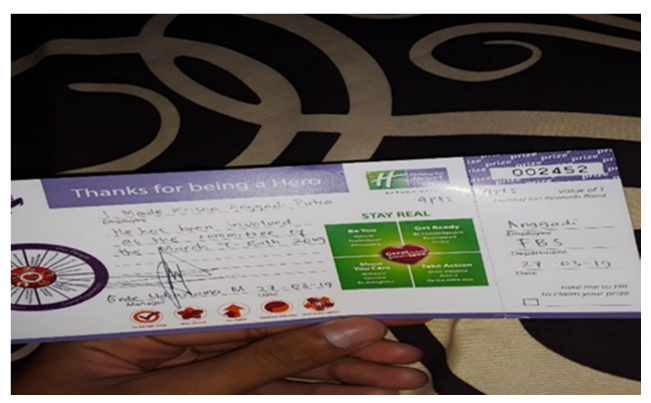

Foto 3 Hero Card

Selain mengadakan pelatihan secara rutin bagi staf, sering juga diadakan gathering bagi para staf, dalam gathering biasanya lebih banyak menyangkut tentang sharering, entertainment dan perjamuan makan.

Penilain kinerja kerja biasanya dilakukan oleh atasan kepada bawahanya, tujuan dilakukankanya penilain kinerja kerja bagi staf diharapkan mampu menumbuhkan rasa motivasi dalam meningkatkan kualitas kerjanya. Ada 5 kriteria yang ditetapkan dalam menilai kinerja pramusaji Palms Restaurant yaitu:

1. Do The Right Thing, bagaimana staf tersebut bekerja sesuai dengan standar yang ditetapkan atau tidak dan apakah staf tersebut bisa memberikan pelayanan yang membuat tamu tersebuat puas.

2. Show We Care, bagaimnaa staf tersebut menunjukan rasa saling menolong bukan hanya kepada tamu namun juga kolega.

3. Aim Higher, bagaimana perkembangan staf tersebut apakah dia yang belum pernah dia capai atau pun mengasah kemampuannya menjadi lebih baik dari sebelumnya. 
4. Celebrate Difference, bagaimana seorang staf menghadapi dan menggapi perbedaan karakter dalam sebuah tim.

5. Work Better Together, bagaimana staf bekerjasama dan membangun hubungan yang baik dengan kolega satu outlet bahkan outlet lainya dalam menjalankan operasional restaurant.

\subsection{Pembahasan Hasil Penelitian}

Berdasarkan hasil penelitian yang sudah saya lakukan strategi yang diterapkan untuk peningkatkan kinerja kerja di Palms Restaurant adalah dengan cara training dan pemberian SOP yang dapat direvisi sesuai dengan perkembangn lingkungan maupun prubahan lainya. Hal ini sama dengan tujuan perencanaan strategi tersebut guna dilakukan meningkatkan kinerja staf untuk menerima persaingan dan perubahan yang terjadi juga mengembangkan keahlian dan pengetahuan staf guna memperlancar operasional dan memcapai target yang ditentukan hal ini didukung oleh pernyataan dari Pearce II dan Robinson (2008), strategi adalah rencana berskala besar, dengan orientasi masa depan, guna berinteraksi dengan kondisi persaingan untuk mencapai tujuan Perusahaan.

Kinerja seorang pramusaji dapat dibangun dari kemauan sendiri maupun dorongan dari lingkungan kerjanya, maka dari itu di Palms Restaurant selalu brusaha mendengarkan masukan satu samalain antar pramusaji maupun atasan dan bawahan, mendiskusikan permasalahn yang terjadi maupun rencana kedepan guna mencapai tujuan bersama. Hal ini dikukung oleh pernyataan Murdijanto (2001:29) bahwa: "Kinerja adalah hasil kerja yang dapat dicapai oleh seseorang atau kelompok orang dalam suatu organisasi sesuai dengan wewenang dan tanggung jawab masing-masing dalam rangka upaya mencapai tujuan organisasi bersangkutan secara legal, tidak melanggar hukum dan sesuai dengan moral maupun etika."

Berdasarkan pembahasan penelitian diatas, implikasi dari penelitian saya adalah pemberian SOP dan perencanaan strategi baru yang sesuai dengan kebutuhan pengembangan staf sangat mengpengaruhi kinerja kerja pramusaji maka dari itu strategi yang dilakukan di Palms Restaurant sudah cukup baik yaitu dengan memberikan SOP sebagai salah satu pedoman kerja dan standar kerja setiap staf di Hotel Holiday Inn Resort Baruna Bali. Akan tetapi akan lebih baik jika pihak manajemen lebih memperhatikan apakah sudah semua stafnya mengaplikasikan SOP secara lansung pada saat proses melayani tamu maupun saat melakukan pekerjaan. Jika ada staf yang tidak mengikuti SOP harus lebih ditindak lanjutin atau diberikan arahan dan masukan yang membangun. Selain itu memberikan training dan gathering merupakan salah satu cara yang cukup efektif untuk membangun rasa nyaman dan lingkungan kerja yang kondusif bagi para karyawan. Dengan 
diadakan pelatihan setiap staf bisa mengetahui kekurangan atau kesalahan yang selama ini mereka lakukan secara sengaja maupun tidak sengaja. Melakukan penilain kinerja juga salah satu strategi yang bagus diterapkan untuk peningkatan kinerja, penilain kinerja bertujuan mengevaluasi bagaimana seorang staf dapat menambah nilai bagi perusahaan. Dengan diadakannya penilaian kinerja diharapkan para staf termotivasi untuk meningkatkan kinerja.

Adapun dampak positif dari strategi yang diterapakan di Palms Restaurant adalah meningkatnya score breakfast tahun lalu, maka dari itu strategi yang diterapkan dirasa sudah cukup baik dan hanya perlu ditingkatkan lagi, tetap menjaga standar kerja dan selalu menerima perubahan.

\section{Penutup}

Dari pembahasan bab-bab yang telah penulis uraikan, maka dapat diambil simpulan, bahwa : Ada beberapa kendala dalam meningkatkan kinerja pramusaji Palms Restaurant yaitu sulitnya melakukan pembaruan bagi staf yang sudah berkerja lama dan masih menggunakan cara yang dulu dilakukan, sulitnya menentukan jadwal pelatihan bagi para pramusaji dikarenakan preparation untuk luncd dan dinner di Palms Restaurant, kekurangan cutleries, lambatnya refill makanan dan menumpuknya pesanan telur saat occupancy tinggi juga berpengaruh bagi kecepatan dan ketepatan kerja pramusaji di Palms Restaurant.

Strategi meningkatkan kinerja pramusaji dipengaruhi oleh faktor individu dan organisasi. Strategi meningkatkan kinerja kerja pramusaji Palms Restaurant dilakukan dengan cara mengadakan training bagi para staf untuk pengemabangan pengetahuan dan ketrampilan kerja, mengadakan gathering guna memperererat hubungan kerja antar staf sehingga dapat berkerja dalam satu kelompok, pemberian kompensasi, pemberian SOP bagi para staf sebagai salah satu acuan standar kerja dan pemberian penghargaan sebagai salah satu apresiasi kerja bagi karyawan beprestasi dan sebagai salah satu motivasi dalam meningkatkan kinerja.

\section{Daftar Pustaka}

Abdulah,M. 2014. Manajemen dan Evaluasi Kinerja Karyawan. Yogyakarta: Penerbit AswajaPressindo.

Anwar,Mangkunegara. 2009. Evaluasi Kerja Sumber Daya Manusia. Bandung: Penerbit Refika Aditama

Bryson,Jhon. 2001. Perencanaan Strategis Bagi Organisasi Sosial. Yogyakarta: Pustaka Pelajar. 
JMPP, Vol 2 No 2, November 2019

p-ISSN: 2654-9719

Guntu dan Yulianto. 2015. Upaya Profesionalisme Kerja Untuk Meningkatkan Pelyanan Tamu Di The Grand Palace Hotel Yogyakarta.Tersedia pada https://scholar.google.co.id/scholar?hl=id\&as sdt=0\%2C5\&q=Upaya+profesionalism e+Kerja+Untuk+Peningkatan+pelayanan+tamu+di+The+Grand+Palace+Hotel+Yogy akarta\&btnG (diaskses pada 5 april 2019)

Kusuma, Arta Adi. 2013. Pengaruh Motivasi Dan Lingkungan Kerja Terhadap Kinerja Staf Hotel Muria Semaarang. Tersedia pada https://scholar.google.co.id/scholar?hl=id\&as sdt=0\%2C5\&q=Pengaruh+Motivasi+D an+Lingkungan+Kerja+Terhadap+Kinerja+Staf+Hotel+Muria+Semaarang\&btnG= (diakses pada tanggal 11 April 2019)

Moelong.Lexy j.2008. Metode Penelitian Kunatitatif Edisi Revisi.Bandung: Penerbit PT.Remaja Rosdakrya.

Murjianto.2001. Manajemen Sumber Daya Manusia. Bina Atmaja: Bandung

Pearce II, Jhon A, dan Robinson Richard B.Jr (2008). Manajemen Strategis 10. Salemba Empat: Jakarta

Sutrisno,Edi. 2009, Manajemen Sumber Daya Manusia Edisi Pertama. Jakarta: Kencana Media Group.

www.google.com 2019. Peta Hotel Holiday Inn Baruna Bali. Tersedia pada https://www.holidayinnresorts.com. 